\title{
Analysis of Chinese Short-Term International Capital Flow Capital Motivation
}

\author{
Feng Qiu \\ Economic Institution, Jinan University, Guangzhou, China \\ Email: Qfjnu2012@163.com
}

How to cite this paper: Qiu, F. (2019) Analysis of Chinese Short-Term International Capital Flow Capital Motivation. Modern Economy, 10, 1062-1071. https://doi.org/10.4236/me.2019.103071

Received: January 28, 2019

Accepted: March 26, 2019

Published: March 29, 2019

Copyright $\odot 2019$ by author(s) and Scientific Research Publishing Inc. This work is licensed under the Creative Commons Attribution International License (CC BY 4.0).

http://creativecommons.org/licenses/by/4.0/

\section{c) (i) Open Access}

\begin{abstract}
Based on the existing basis, this paper analyzes the short-term international working capital. In addition to considering the interest rate, exchange rate and asset price factors, it also incorporates the fluctuation risk factors of GDP for comprehensive consideration. This article uses the quarterly data of 2000Q1-2016Q3 to build a VAR model of quarterly data. The results show that Chinese short-term international capital flows are explained by their own changes to a large extent; among the four factors, exchange rate and asset price factors have the greatest impact, and arbitrage and DGP risk fluctuations have the weakest impact, indicating that investors are at the national level. Economic fluctuations and spreads are not sensitive, and the purpose of short-term international capital is to obtain the benefits of assets and exchange rates.
\end{abstract}

\section{Keywords}

Short-Term International Capital Flows, Interest Rates, Exchange Rates, Asset Prices, GDP Risk Fluctuations, VAR

\section{Introduction}

In 1997, the financial crisis in Asia broke out, raising concerns about short-term capital flows in developing countries. With the gradual relaxation of Chinese accession to the WTO and foreign exchange controls in 2001, Chinese short-term international capital flows have increased. In recent years, existing research has shown that extreme changes in short-term international capital flows will have an important impact on the stability of a country's financial system. Rothenberg and Warnock (2011) mentioned that the volatility of short-term international capital has broad economic impacts, such as accelerating the economic cycle, making a country's financial system vulnerable and aggravating overall macroe- 
conomic instability. However, short-term international capital flows can also be benign and even bring substantial benefits. Therefore, it is of great significance to study the factors affecting short-term international capital flows.

\section{Literature Review}

With the deepening of the globalization process, international capital flows have shown a momentum of rapid growth. International capital flows can be divided into short-term international capital flows and long-term international capital flows according to the length of time. This paper mainly reviews the literature on short-term international capital flows. Short-term international capital flows are understood literally as the inflow and outflow of capital within a year or a year. At the same time, short-term international capital can be divided into trade flows, financial capital flows and speculative capital flows according to motivation, while speculative capital flows are often called hot money. The short-term international capital flow anomaly will have an impact on the stability of a country's economic and financial, so it is of great significance to conduct research on short-term international capital.

The early theory of the factors affecting international capital flows is basically discussed from the perspective of capital arbitrage, which can be roughly summarized as the theory of interest rate decision, the joint effect of interest rate and exchange rate, the theory of asset portfolio, the role of monetary policy, and the determination of transaction costs. Recent research has focused on the drivers of capital flows between developed and developing countries, as well as the actual impact of international capital flows on developing countries. Calvo et al. \& Reinhart (1993) explored the characteristics of capital inflows in Latin America and pointed out that external factors (the US economic recession and international spreads) played an important role [1]. Lucas (1990) proposed that the quality of human capital and the degree of perfection of the capital market have an important impact on international capital flows [2]. Alfaro et al. (2008) used empirical evidence to further explain the "Lucas Paradox" and explore cross-country differences in human capital and capital market imperfections. This article uses panel data to test the decisive factors of total capital inflows [3]. Joseph P. Byrne (2016) validates long-term bond yields and commodity prices as a determinant of global capital flows while studying international capital flows in emerging markets, as well as the country's own capital account openness and financial institutions [4].

With the continuous improvement of economic openness, Chinese research on short-term international capital flows has gradually become a hot spot. China's research in this area can be divided into two main areas. The first aspect is about the calculation of the scale of China's short-term international capital flows. Another aspect is about the factors affecting China's short-term international capital flows.

The calculation of the scale of Chinese short-term international capital flows is mainly based on the methods commonly used abroad: direct, indirect and hy- 
brid. In terms of the influencing factors, Chinese scholar Wang Yang (2004) proposed that China's capital flow is more affected by interest rates, and the exchange rate factor is not significant due to the influence of China's exchange rate control [5]. Wang Qi (2006) found that exchange rate, interest rate, inflation rate and policy variables all affect the impact of China's short-term international capital flows [6].

Chen Xuebin (2007) empirically analyzed the situation of China's international capital flows from 2000 to early 2007 by establishing a cointegration equation for China's long-term and short-term capital inflows. It was found that the strong appreciation of the RMB is expected to be attractive to short-term capital inflows [7]. Chen Langnan (2009) proposed that the RMB exchange rate, domestic and international spreads and real estate yields have significant lag effects on short-term international capital flows. In the long run, the expected rate of change of RMB exchange rate and domestic and international spreads are significant factors affecting short-term international capital flows. The RMB exchange rate, domestic stock market returns and real estate yields have not had a significant impact on short-term international capital flows [8]. Liu Liya (2013) examined the relationship between capital controls and international capital flows. The empirical results show that capital controls will increase domestic output shocks, resulting in very limited effect of capital controls on international capital flows [9].

Scholars generally believe that the factors affecting short-term international capital flows are: Interest rate, exchange rate and asset prices, in addition to the view that some scholars from the capital-exporting countries and capital importing countries two angles to analyze the causes of short-term international capital flows. The main innovation point of this paper is based on the previous basis to study the factors of China's short-term international capital flow, and from the macroscopic and microscopic two angles of analysis.

\section{Model Selection and Description of Variable Data}

\subsection{Model Selection}

This paper uses the VAR model to analyze the driving factors of China's short-term international capital flows. The reason for using the VAR model for analysis is that it constructs the model by using each endogenous variable in the system as a function of the hysteresis value of all endogenous variables in the system. It is not necessary to distinguish the endogenous and exogenous nature of the variable, and it can also use real Data describes the dynamic relationship between multiple variables. The form of the VAR model, as in

$$
y_{t}=\varphi_{1} y_{t-1}+\cdots+\varphi_{p} y_{t-p}+\varepsilon_{t}, \quad t=1,2, \cdots, T
$$

where $y_{t}$ is the $K$-dimensional endogenous variable column vector, $P$ represents the lag order, $T$ is the number of samples, $\varphi_{1}, \cdots, \varphi_{p}$ represents the coefficient matrix of the $K \star K$ dimension to be estimated, and $\varepsilon_{t}$ represents the $K$-dimensional impulse vector. 
The VAR model includes short-term international capital inflows to SC and three major influencing factors-interest rates, exchange rates, and asset prices-and also includes risk factors for GDP volatility. Among them, the interest rate has chosen the Sino-US spread ID variable, which reflects the arbitrage factor. The exchange rate draws on the methods of Chen Langnan and Chen Yun (2009), and chooses two variables, the RMB exchange rate change rate ERY and the RMB exchange rate expected change rate NDF, reflecting the arbitrage factor; The asset price selected the stock price return rate MKT of the Shanghai Composite Market and the rate of return of the national housing boom index to reflect the set price factor in the short-term international capital inflow; finally, the quarterly volatility of GDP was used to measure the risk factor. Thus VAR contains a total of seven variables, namely SC, ID, ERY, NDF, MKT, House, GDP.

\subsection{Description of Variable Data}

This paper selects the data sample from the first quarter of 2000 to the third quarter of 2016 in Wind, including the significant changes in short-term international capital inflows two years before China's accession to the WTO, and the use of quarterly data because of the availability of data. Both the sex and the sample size of the data are ideal.

- The short-term international capital inflow size SC is measured by the direct method. Here, Zhang Yi (2007)'s method is borrowed, and the method is to draw on and promote Claessens \& Naude (1993) on "the method of calculating the hot money 3" and relax the measurement caliber. Calculation formula: Short-term international capital inflow (SC) = initial income lender under current account (CI) + credit balance of securities investment under capital and financial items (FI) + [other short-term investment credit balance under financial items + net error and omission project] (ST)

- Other short-term investment credit balances under financial projects $=$ financial derivative credit balance + currency and deposit credit balance + loan credit balance + trade credit credit balance + other short-term investment credit balance

- The specific situation is shown in Figure 1. The short-term international capital inflows from 2000 to 2007 showed a small fluctuation and a steady growth trend; and in the second half of 2007, the financial crisis began, and the fluctuation of short-term international capital inflows increased. Large, we can see that the financial crisis began to intensify in the financial crisis in 2008, and then gradually inflows, showing the characteristics of two-way flow; after 2013, short-term international capital has experienced a large-scale "flight" phenomenon.

- Domestic and foreign spread ID. This paper adopts the representative spread of China and the United States to express the arbitrage factor income, and selects the one-year deposit interest rate of China and the US federal oneyear interest rate as the representative interest rate. 


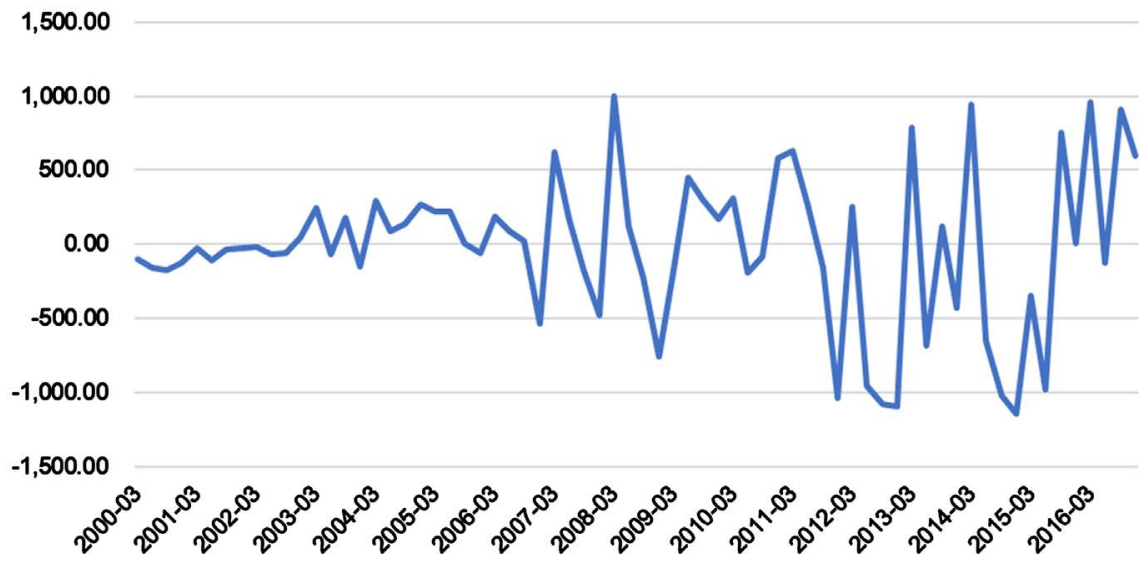

Figure 1. 2000Q1-2016Q3 short-term international capital inflows of China (100 million RMB). Source: Wind.

- $\mathrm{RMB}$ exchange rate change rate ERY and RMB expected exchange rate change rate NDF. The exchange rate between the US dollar and the Chinese yuan is selected here. Since the Chinese capital project has not yet been fully opened, the choice here is the one-year RMB NDF exchange rate change as a proxy variable for the expected exchange rate of the RMB. The rate of change of both exchange rates uses a logarithmic logarithmic rate of return.

- Stock price change rate MKT and real estate price change rate House. This paper uses the SSE composite index to compare the "set price" factor of the stock market and the rate of change of the national housing climate index compiled by the National Bureau of Statistics to measure the "set price" factor of the real estate market.

- Quarterly volatility of GDP. The volatility of the quarterly GDP compiled by the National Bureau of Statistics is used to measure risk factors at the national level.

\section{VAR Model Construction Process}

\subsection{Unit Root Test}

First, the ADF test is used to perform the unit root test. The purpose is to ensure that the variables entering the VAR model are stable. Otherwise, non-stationary variables entering the model will cause the model itself to be unstable. It can be seen from Table 1, we can see that the ADF test value of ID is -2.12 , which is less than the Threshold -3.47 , and GDP is -2.72 , which is less than the Threshold -3.48 . Other factors are all stationary sequences.

We find that the first-order difference sequence of ID and GDP is stable, so we use DID and DGDP in VAR Model.

\subsection{Model Identification and Determination of Lag Order}

In the VAR model, the order of the variables will affect the estimation results, especially the analysis of the impulse influence function and the analysis of the variance decomposition results, resulting in poor reliability of the conclusion. 
Table 1. ADF test results of VAR model variables.

\begin{tabular}{ccccc}
\hline Variable & ADF Test value & Type $(\mathrm{c}, \mathrm{t}, \mathrm{k})$ & Threshold (5\%) & result \\
\hline SC & -4.468592 & $(\mathrm{c}, \mathrm{t}, 0)$ & -3.479367 & smooth \\
ID & -2.121043 & $(\mathrm{c}, \mathrm{t}, \mathrm{0})$ & -3.479367 & Non-smooth \\
ERY & -5.199110 & $(\mathrm{c}, \mathrm{t}, 0)$ & -3.479367 & smooth \\
NDF & -6.275139 & $(\mathrm{c}, \mathrm{t}, 0)$ & -3.479367 & smooth \\
MKT & -6.536636 & $(\mathrm{c}, \mathrm{t}, 0)$ & -3.479367 & smooth \\
House & -5.137614 & $(\mathrm{c}, \mathrm{t}, 2)$ & -3.481595 & smooth \\
GDP & -2.723965 & $(\mathrm{c}, \mathrm{t}, 2)$ & -3.483970 & smooth \\
DID & -9.583127 & $(\mathrm{c}, \mathrm{t}, 2)$ & -3.480463 & smooth \\
DGDP & -4.826615 & $(\mathrm{c}, \mathrm{t}, 2)$ & -3.492149 & smooth \\
\hline
\end{tabular}

Note: $(c, t, k) c$ represents a constant term representing a time trend term, and p represents a lag order, determined according to the AIC criteria.

Here, Eviews8.0 Granger causality test is used to determine the economic significance. The order of Cholesky decomposition is: House, DGDP, NDF, ERY, DID, MKT.

Regarding the determination of the model lag order $\mathrm{P}$, the maximum possible lag order is selected as the fifth order, and the logarithm of all possible lag orders is obtained. According to the AIC and SC criteria, the optimal lag order is 5 and 0 , respectively, and the LR and HQ are 3 orders. Considering the inconsistency of various judgment results, the LR judgment result is used here to determine the lag order. 3rd order. After further AR eigenvalue test, it is found that all the reciprocals fall within the unit circle, indicating that the lag order 3 is reasonable and the model is stable.

\section{VAR Model Results Analysis}

Using EVIEWS 8.0 software, based on the VAR estimation, the impact period of the considered impact is set to 12 , and the impulse is set to a residual of 1 unit. In Figure 2, the impulse response of each variable shock to short-term international capital inflow can be calculated. The contribution of the function and its variance changes.

\subsection{Analysis of Impulse Response Function of Each Variable Impact}

- When the positive impact of a unit of short-term international capital flows (SC) occurs, its own response is the largest in the first period of 479.1078, then gradually decreases, and the second period is reduced to half. After the third period, it will be reduced to a lesser degree. The value, after which the volatility decreases, continues into the seventh period. This shows that China's short-term international capital itself has an inertia of about six months. 

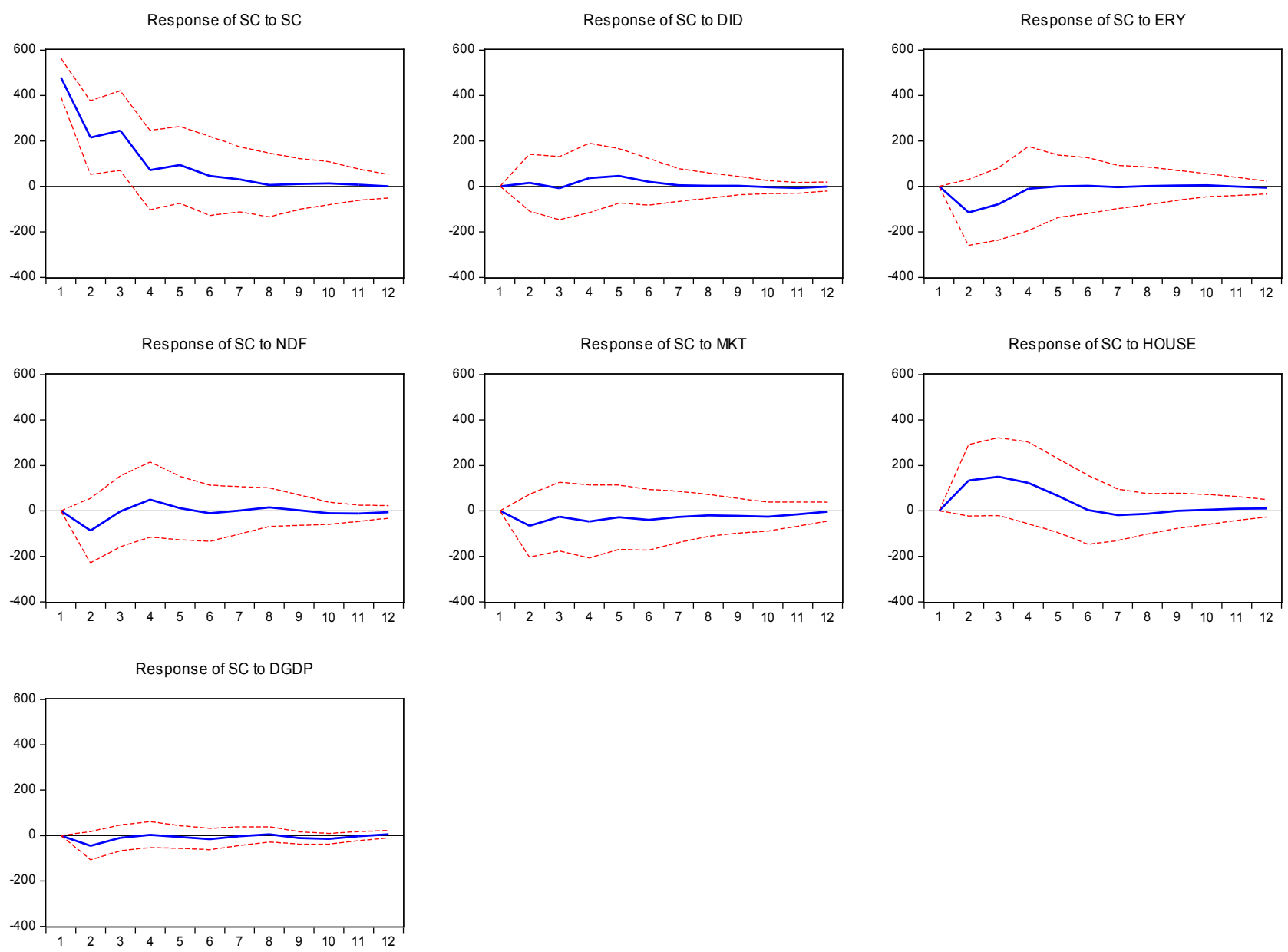

Figure 2. Impulse response function of short-term international capital flow (SC) impact on various variables.

- After a positive impact from China-US spread (DID), short-term international capital inflows did not respond to SC in the first period. Before the fourth period, the short-term international capital flows SC fluctuated around zero, then reached the maximum of 46.52 units in the fifth period, after which the impact began to become smaller, indicating that the Sino-US spreads for short-term international capital inflows The attraction is smaller, but the duration is longer. Mainly because the current interest rate in China has not been fully liberalized, international capital must stay longer for a longer period of time to obtain better "arbitrage" income.

- After being positively impacted by the RMB exchange rate change rate (ERY) of 1 unit, short-term international capital flows did not change in the first period, while short-term international capital flows showed a net outflow after the second period, which was reached in the third period. The minimum value is -114.72 units, which is rapidly weakened after the third period, and the negative impact is reduced. After that, it fluctuates around zero. This shows that short-term international capital flows are sensitive to changes in the RMB exchange rate.

- After being positively affected by the expected rate of change of the RMB ex- 
change rate, the short-term international capital flows did not change in the first period, but after the second period, the net outflows reached a minimum of -85.88 units. After the third period, it showed a net inflow and reached a maximum of 47.37 in the fourth period, and this effect lasted longer. This shows that the impact of expected changes in the RMB exchange rate on international capital flows is unpredictable and sustainable, and international capital is more sensitive to expected exchange rate factors.

- When the stock price return (MKT) produces a positive impact on one unit, international capital flows are characterized by a continuous net outflow, although this effect slowly decreases over time, but lasts longer. After a one-unit positive impact on the real estate price change house, short-term international capital flows did not respond in the first period, while in the second to fifth periods, there was a continuous net inflow and reached a maximum of 150.50 in the third period. Units, while fluctuations after the fifth period, continued until the 12th period. Short-term international capital is more sensitive to real estate change rates and lasts longer. These characteristics are likely to be related to the long-term trading of Chinese real estate transactions and the stricter restrictions on foreign investment.

- When the GDP volatility initiates a positive unit shock, short-term international capital presents a net outflow, and the impact after the third period decreases rapidly, which is related to short-term international capital risk aversion.

\subsection{The Variance Decomposition of Short-Term International Capital Flow}

From the results of Table 2, in the first month, the short-term international capital flow forecasting variance is completely explained by its own changes. In the long run, about $20 \%$ of the short-term international capital flow variance can be determined by other factors, and we can see from the Table 2 that the House price factor accounts for more than 50\%, and the exchange rate accounts for $20 \%$ more or less. Among them, the asset price factor has the highest degree of interpretation. The stock change rate(MKT) are about $10 \%$ and NDF explains the degree of $25 \%$ and $10 \%$ respectively; The China-US spread (DID) and gross domestic product risk volatility (GDP) account for only about 5\%. It can be seen from the above that the current "set price" and "arbitrage" are the main factors attracting the entry of short-term international capital, while the "arbitrage" factor and the impact of GDP risk fluctuation are the least, which means that the main purpose of short-term international capital inflow is to Take the stock market and real estate and other asset market price returns while waiting for the people to appreciate. After the September 11th incident in 2001, the market's confidence in the US dollar was hit. With the rise of China's economic strength, the RMB exchange rate unilaterally strengthened and continued to appreciate steadily, which in turn attracted short-term international capital to flow into China. At the same time, after 2007, the stock market and real estate market 
Table 2. Short-term international capital flow forecasting variance decomposition results.

\begin{tabular}{ccccccccc}
\hline T & SC (\%) & Variable factor (\%) & DID & ERY & NDF & MKT & HOUSE & DGDP \\
\hline $\mathbf{1}$ & 100.00 & 0.00 & 0.00 & 0.00 & 0.00 & 0.00 & 0.00 & 0.00 \\
$\mathbf{2}$ & 85.98 & 14.02 & 0.53 & 29.29 & 16.42 & 9.49 & 39.76 & 4.51 \\
$\mathbf{3}$ & 81.84 & 18.16 & 0.41 & 25.77 & 9.91 & 6.60 & 54.43 & 2.87 \\
$\mathbf{4}$ & 78.07 & 21.93 & 1.73 & 20.16 & 10.27 & 7.40 & 58.20 & 2.24 \\
$\mathbf{5}$ & 77.20 & 22.80 & 3.70 & 18.69 & 9.67 & 7.63 & 58.19 & 2.12 \\
$\mathbf{6}$ & 76.90 & 23.10 & 4.00 & 18.28 & 9.56 & 8.95 & 56.90 & 2.32 \\
$\mathbf{7}$ & 76.77 & 23.23 & 3.99 & 18.10 & 9.47 & 9.50 & 56.64 & 2.30 \\
$\mathbf{8}$ & 76.63 & 23.37 & 3.97 & 17.96 & 9.63 & 9.79 & 56.34 & 2.30 \\
$\mathbf{9}$ & 76.53 & 23.47 & 3.95 & 17.87 & 9.58 & 10.18 & 56.01 & 2.40 \\
$\mathbf{1 0}$ & 76.37 & 23.63 & 3.93 & 17.72 & 9.59 & 10.69 & 55.50 & 2.57 \\
11 & 76.29 & 23.71 & 3.95 & 17.64 & 9.66 & 10.84 & 55.35 & 2.57 \\
$\mathbf{1 2}$ & 76.25 & 23.75 & 3.94 & 17.63 & 9.66 & 10.82 & 55.35 & 2.59 \\
\hline
\end{tabular}

prices soared, further attracting short-term international capital into the two asset price markets to obtain double income from arbitrage and set prices.

\section{Conclusions}

This paper first selects seven variables including short-term international capital flow and arbitrage, arbitrage, set price and GDP volatility. The 2000Q1 and 2016Q3 quarter data are used to construct the VAR model. Then, the impulse response function and variance decomposition techniques are used to analyze the VAR model. The driving factors are four types of factors for short-term international capital flows. The results show that China's short-term international capital flows are explained by their own changes to a large extent, showing the characteristics of strong volatility and poor predictability. Among the four factors, the contribution of "set price" and "arbitrage" factors Larger, "arbitrage" and economic fluctuations at the national level are weaker. It can be shown that the reason for the short-term international capital inflow to the domestic market is mainly to capture the "price" income of capital markets such as stocks and real estate, while waiting for the appreciation of the renminbi. This result is closely related to the Chinese foreign exchange market and the real estate market. Of course, the flaw of this paper is that it does not consider the macro factors of the impact of short-term international capital flows, in the interpretation of micro-influencing factors, there is no in-depth analysis of real estate and exchange rate factors have the greatest impact.

\section{Suggestions}

The supervisory authority should improve the monitoring, early warning and management mechanism for short-term international capital inflows as soon as possible, strictly monitor the formal inflow of short-term international capital, 
prevent the informal inflow of short-term international capital, and increase the punishment for short-term international capital for illegal entry. The transaction costs of short-term international capital speculators increase the risk of arbitrage and hedging. Secondly, accelerate the formation of a real market mechanismbased RMB exchange rate formation mechanism, enhance the flexible exchange rate response mechanism, realize the $\mathrm{RMB}$ clearing exchange rate and equilibrium level as soon as possible, weaken the expectation of RMB exchange rate unilateral rise and fall, and thus weaken short-term international capital inflows. Finally, while stabilizing domestic real estate and stock markets through various measures, we will strengthen supervision over the large-scale entry of foreign capital into the real estate market and the stock market, especially to curb speculative purchases by foreign investors.

\section{Conflicts of Interest}

The author declares no conflicts of interest regarding the publication of this paper.

\section{References}

[1] Calvo, G.A., et al. (1993) Capital Inflows and Real Exchange Rate Appreciation in Latin America: The Role of External Factors. Staff Papers, 40, 108-151.

[2] Lucas (1990) Why Doesn't Capital Flow from Rich to Poor Countries? American Economic Review, 80, 92-96.

[3] Alfaro (2008) Why Doesn't Capital Flow from Rich to Poor Countries? An Empirical Investigation. The Review of Economics and Statistics, 90, 347-368.

[4] Byrne, J.P. and Fiess, N. (2016) International Capital Flows to Emerging Markets: National and Global Determinants. Journal of International Money and Finance, 61, 82-100. https://doi.org/10.1016/j.jimonfin.2015.11.005

[5] Wang, Y. (2004) Research on Capital Flow in China since 1994. International Finance Research, 6, 67-73.

[6] Wang, Q. (2006) Construction and Analysis of the Econometric Model of Influencing Factors of China's International Capital Flows. International Finance Research, 6, 64-69.

[7] Chen, X.B., Yu, C.J. and Sun, Y.F. (2007) Empirical Analysis of the Influencing Factors of China's International Capital Inflow. International Finance Research, 12, 53-60.

[8] Chen, L.N. and Chen, Y. (2009) RMB Exchange Rate, Asset Price and Short-Term International Capital Flows. Economic Management, 1, 1-6.

[9] Liu, L.Y., Cheng, T.X., Guan, Y.Z. and Yang, J.Q. (2013) Can Capital Control Affect International Capital Flows? Economic Research, 48, 33-46. 